\title{
Methods of optimizing the phosphate regime of drained peat soils in the northern trans-Urals
}

\author{
Anatoly Iglovikov ${ }^{1, *}$, and Alexander Motorin ${ }^{2}$ \\ ${ }^{1}$ Northern Trans-Ural State Agricultural University, Republic str., 7, Tuymen, 625003, Russia \\ ${ }^{2}$ Tyumen Research Centre, Siberian branch of the Russian Academy of Sciences, Malygina, 86, \\ Tuymen, 625026, Russia
}

\begin{abstract}
The paper presents the results of long-term research to determine the content of phosphorus in drained peat soils and the influence of agro-meliorative techniques on its dynamics. The objects of research were medium-power peat soils on the typical genesis for subtaiga (Yernyakul bog located on the watershed of Tobol and Vagai rivers; Usalskoe bog - on the second floodplain terrace of Tobol river) and forest steppe (Tarmanskoe bog, Reshetnikovo object located on the second floodplain terrace of Tura river) of Northern Trans-Ural region. It has been revealed that the gross phosphorus content in drained peat soils is $0.1-0.3$ $\%$. The main part (83.8-95.2\%) of phosphorus in peat soil is in the form of organic compounds. The ratio of mobile phosphorus to its gross content corresponds to $4.8-16.2 \%$. The mobility of phosphorus during the 40summer period increases insignificantly and only in the arable layer. The increase in the content of phosphorus is achieved by the use of phosphorus fertilizers and, to a lesser extent, the strengthening of the processes of mineralization of peat. Poor mobility and good availability of phosphorus plants on peat soils allows to put it in stock for 5 years.
\end{abstract}

\section{Introduction}

Studies in different regions of our country indicate low provision of peat soils with phosphorus, which, as a rule, is about $0.05-0.2 \%$ of absolutely dry soil. Only in some peat soils it sharply increases up to $0.5-4.0 \%$ due to vivianite layers [1-4]. Low content of gross and mobile forms of phosphorus is also established in peat soils of Siberia [5-7].

The total stock of gross phosphorus is not always an indicator of the availability of phosphoric acid in plants [8]. The main part (50-95\%) of phosphorus in peat soil is in the form of organic compounds, which are available to plants only after their mineralization [9]. The accumulation of mobile phosphorus due to its accumulation in root residues and mineralization of organic matter of peat occurs very slowly. If organic matter containing less than $0.2-0.3 \%$ phosphorus is mineralized in the soil, it does not release mineral compounds available to plants, it is fully bound by microorganisms [10]. Therefore, phosphate fertilizers play an extremely important role. Without the application of

\footnotetext{
* Corresponding author: an.iglovikov@mail.ru
} 
phosphorus fertilizers on newly developed peat soils, it is impossible to grow crops that would pay for their cultivation [11].

The analysis of peat soils use in the Northern Trans-Urals shows that cultivation of agricultural crops without taking into account the phosphate regime does not give the proper effect. The phosphate regime of peat soils in the region is not sufficiently studied. In this connection, we have carried out long-term researches.

The aim of the study is to determine the content of phosphorus in drained peat soils and the influence of agroreclamation techniques on its dynamics.

\section{Objects and methods of the research}

The objects of the research were medium-power peat soils typical for the genesis of sub taiga and forest-steppe of the Northern Trans-Ural region. Field stationary studies were conducted in 1973-2013.

Medium-power peat soils have low ash content (4.7-7.2\%), weakly acidic reaction of the environment ( $\mathrm{pH}$ salt 5.2-6.2), relatively high hydrolytic acidity (21.2-40.8 mg.eq/100 $\mathrm{g}$ of soil), low saturation of bases (62-85\%) [12].

\section{Results and discussion of the research}

As a result of our researches it is established that the initial content of gross phosphorus in an arable layer of peat soils changes in a range from 0,11 to $0,30 \%$. Down the profile its amount is reduced by 1.4-4.3 times (Table 1). The main reason for the accumulation of phosphorus in the root zone is the intensity of its biological cycle, which provides multiple cyclic processing of phosphate material. This factor explains the regularity of the increase of phosphorus reserves in the upper horizons with its relative decrease in the lower horizons. Low reserves of phosphorus in peat are primarily due to the chemical composition of peat plants.

Table 1: Gross phosphorus content in medium-power peat soils, $\%$

\begin{tabular}{|c|c|c|c|c|c|c|}
\hline \multirow{2}{*}{$\begin{array}{c}\text { Depth, } \\
\mathrm{m}\end{array}$} & \multicolumn{2}{|c|}{ Yernyakul } & \multicolumn{2}{c|}{ Usalka } & \multicolumn{2}{c|}{ Reshetnikovo } \\
\cline { 2 - 7 } & $\begin{array}{c}\text { Before the } \\
\text { experiment }\end{array}$ & $\begin{array}{c}\text { In } 40 \\
\text { years }\end{array}$ & $\begin{array}{c}\text { Before the } \\
\text { experiment }\end{array}$ & $\begin{array}{c}\text { In 36 } \\
\text { years }\end{array}$ & $\begin{array}{c}\text { Before the } \\
\text { experiment }\end{array}$ & $\begin{array}{c}\text { In 32 } \\
\text { years }\end{array}$ \\
\hline $0-0,2$ & 0,11 & 0,19 & 0,30 & 0,20 & 0,12 & 0,24 \\
$0,2-0,4$ & 0,16 & 0,17 & 0,12 & 0,09 & 0,14 & 0,15 \\
$0,4-0,6$ & 0,13 & 0,11 & 0,10 & 0,06 & 0,14 & 0,16 \\
$0,6-0,8$ & 0,08 & 0,09 & 0,08 & 0,07 & 0,11 & 0,12 \\
$0,8-1,0$ & 0,08 & 0,05 & 0,07 & 0,08 & 0,09 & 0,10 \\
\hline
\end{tabular}

Long-term studies have established a reduction in gross phosphorus reserves at the Usalka site. Here, the gross phosphorus content is reduced throughout the entire soil profile, especially in the upper 0.2 -meter layer (by $50 \%$ ). This fact is explained by growing perennial grasses without phosphorus fertilizers on the experimental plot.

Application of 60-90 kg of phosphorus fertilizers per hectare for 18 years (Yernyakul bog) and 13 years (Reshetnikovo facility) ensured the increase of gross phosphorus reserves in the arable layer.

Phosphorus has poor mobility due to its strong fixation with peat (Table 2). The ratio of mobile phosphorus to gross phosphorus in peat soils from the Yernyakul bog before the establishment of the experiment was 4.8-6.6\%. The content of mobile phosphorus in peat soil was higher (31.2-89.6 kg/ha) in the Usalka swamp and varied in profile in relation to its gross quantity from 11.1 to $16.2 \%$; in Reshetnikovo object - from 5.1 to $9.1 \%$. The 
obtained long-term data confirm that the main part of phosphorus is represented by organic compounds. Phosphorus mobility has increased insignificantly during the 40 -year period and only in the arable layer.

Table 2: Stocks of gross and mobile phosphorus in medium-power peat soil (Yernyakul swamp)

\begin{tabular}{|c|c|c|c|c|c|c|}
\hline \multirow{2}{*}{ Depth, $\mathrm{m}$} & \multicolumn{3}{|c|}{ Before the experiment } & \multicolumn{3}{c|}{ In 40 years } \\
\cline { 2 - 7 } & \multicolumn{5}{|c|}{ Fosfor, kg/ga } \\
\cline { 2 - 7 } & gross & mobile & \% to gross & gross & mobile & \% to gross \\
\hline $0-0,2$ & 323,4 & 17,1 & 5,3 & 675,0 & 54,4 & 8,0 \\
$0,2-0,4$ & 489,6 & 32,1 & 6,6 & 574,0 & 34,8 & 6,1 \\
$0,4-0,6$ & 364,0 & 20,4 & 5,6 & 385,0 & 22,1 & 5,7 \\
$0,6-0,8$ & 219,2 & 10,4 & 4,8 & 306,0 & 12,9 & 4,2 \\
$0,8-1,0$ & 216,0 & 11,3 & 5,3 & 215,0 & 12,5 & 5,8 \\
\hline
\end{tabular}

The main amount of mobile phosphorus by the beginning of peat soil development is concentrated in the upper 0.4-meter layer.

The analysis of the obtained data shows that without fertilizer application in the medium-duty peat soil there is accumulation of little phosphorus available to plants, especially in the podkhatitny layer. Under perennial grasses, the movement of phosphorus in the soil is more limited.

Table 3: Mobile phosphorus content in the arable layer of medium-power peat soil under perennial grasses (Reshetnikovo), mg/100 g of soil (no fertiliser has been applied since 1986)

\begin{tabular}{|c|c|c|c|c|c|c|}
\hline \multirow{2}{*}{$\begin{array}{l}\text { Variant of the } \\
\text { experiment }\end{array}$} & \multicolumn{6}{|c|}{ Years } \\
\hline & 1981 & 1985 & 1986 & 1991 & 2008 & 2013 \\
\hline Without fertilizers & 12,3 & 13,8 & 12,9 & 11,9 & 8,3 & 6,9 \\
\hline $\mathrm{N}_{60} \mathrm{P}_{90} \mathrm{~K}_{90}$ & 29,6 & 63,8 & 59,7 & 27,2 & 9,2 & 8,7 \\
\hline
\end{tabular}

Stop applying phosphate fertilizer immediately affects its content in the soil. The most noticeable decrease has occurred since the third year of the effect (Table 3). At the same time, after 6 years the content of mobile phosphorus in the arable layer of soil was 2.3 times higher than in the control plots. This fact confirms the high efficiency of the effect of phosphate fertilizers.

Table 4: Content of mobile phosphorus in the arable layer of medium-power peat soil depending on the type and norm of mineral fertilizers (Yernyakul), $\mathrm{mg} / 100 \mathrm{~g}$ of soil

\begin{tabular}{|c|c|c|c|c|c|c|}
\hline Type and standard of fertilizers & \multicolumn{5}{|c|}{ A year after applying } & Average \\
& 1 & 2 & 3 & 4 & 5 & $\begin{array}{c}\text { for 5 } \\
\text { years }\end{array}$ \\
\cline { 2 - 6 } & 6,9 & 9,1 & 12,0 & 10,3 & 8,6 & 9,4 \\
\hline Without fertilizers & 39,1 & 42,0 & 43,0 & 40,5 & 29,7 & 38,9 \\
\hline $\mathrm{P}_{\mathrm{f} 240}$ in stock & 46,6 & 51,2 & 50,6 & 55,2 & 46,8 & 50,1 \\
\hline $\mathrm{P}_{\mathrm{f} 240}$ in stock $+\mathrm{K}_{120}$ annually & 48,2 & 62,8 & 68,0 & 60,3 & 40,5 & 55,9 \\
\hline $\mathrm{P}_{\mathrm{f} 240}$ in stock $+\mathrm{N}_{60} \mathrm{~K}_{120}$ annually & 71,7 & 64,3 & 70,1 & 68,0 & 59,6 & 66,7 \\
\hline $\mathrm{P}_{\mathrm{f} 360}$ in stock $+\mathrm{N}_{60} \mathrm{~K}_{120}$ annually & 6,7 & 9,5 & 12,9 & 11,5 & 6,8 & 9,5 \\
\hline $\mathrm{N}_{60} \mathrm{~K}_{120}$ annually & 11,2 & 15,9 & 14,0 & 23,0 & 29,6 & 20,7 \\
\hline $\mathrm{P}_{\mathrm{c} 60}$ annually & & & & &
\end{tabular}

Poor mobility and good availability of phosphorus plants on peat soils allows for a number of years' supply of phosphorus. This contributes to a rapid increase in phosphate levels (Table 4). The mobile phosphorus content increases in the first year of application, 
especially when using $360 \mathrm{~kg}$ of phosphorus per hectare. Subsequent years, mobile phosphorus reserves in this variant decreased, but at the same time remained the highest. Unused phosphate rock phosphorus remains in the soil mainly in the form of calcium phosphate and is more available to plants later than residual superphosphate phosphorus, which is transformed into hard-to-reach compounds. This property of phosphorite flour favors its use on peat soils and contributes to a longer fertilizer action. For more efficient use, phosphorus should be applied to the soil well in advance. Joint application of nitrogenphosphorus fertilizers, and then in the form of annual top dressing at the rate of N60K120 increased the content of mobile phosphorus on average for five years by $17 \mathrm{mg} / 100 \mathrm{~g}$ of soil compared to pure phosphorus. Annual application of physiologically acidic fertilizers has an acidifying effect on the reaction of the soil solution, which accelerates the process of transition of phosphorus from phosphorus to mobile form. Independent application of potassium-nitrogen fertilizers does not affect the content of mobile phosphorus in the soil.

When phosphorus flour is added to the reserve, the mobile phosphorus content in the soil drops sharply after five years due to its consumption by perennial grasses. In contrast, the annual application of $60 \mathrm{~kg}$ of EP/ha of superphosphate increases the amount of mobile phosphorus by a factor of 2.6.

\section{Conclusion}

1. The gross content of phosphorus in the medium-power peat soils of the Northern Trans-Urals is $0.1-0.3 \%$. The main part (83.8-95.2\%) of phosphorus in peat soils is in the form of organic compounds and is available to plants only after their mineralization.

2. Phosphorus has poor mobility due to the strong fixation of its peat. The ratio of mobile phosphorus to gross phosphorus is $4.8-16.2 \%$. Mobility of phosphorus during the 40 -summer period increases insignificantly and only in the arable layer.

3. The increase in the content of gross and mobile phosphorus is achieved by the use of phosphorus fertilizers and, to a lesser extent, by the strengthening of the processes of mineralization of peat, because peat-forming plants contain little phosphorus. Introduction of $120 \mathrm{~kg}$ of d.v./ha of phosphorus increases stocks of its mobile forms in the first year 4 times and 3-4 times exceeds the yield of perennial grasses.

4. Poor mobility and good availability of phosphorus plants on peat soils allows to reserve it for a number of years. The application of phosphorus meal in the norm of $360 \mathrm{~kg}$ b.p./ha in the reserve for 5 years favours its use on peat soils and contributes to a longer action.

\section{References}

1. A.S. Motorin, A.V. Iglovikov Izvestiya Orenburg State Agrarian University 6(74), 12 15. (2018)

2. I.N. Skrynnikova Soil processes in cultivated peat soils. Moscow: USSR Academy of Sciences, (1961)

3. A.S. Motorin Swamps and biospheres materials of All-Russian with international participation of X school of young scientists. pp. 297-302. (2018)

4. L.N. Karetin Soils of the Tyumen Region. Novosibirsk: Science, Sib., 286 p.

5. E.A. Gordeeva Scientific works of SevNIIGiM, 39, 159-180. (1969)

6. A.V. Iglovikov, A.S. Motorin, A.V. Bukin IOP Conference Series: Earth and Environmental Science electronic edition. 082026, (2018) 
7. N.G. Ore Cultivation and agricultural use of peat soils in Central Siberia. Krasnoyarsk, 73-85. (1978)

8. A.V. Bukin, A.S. Motorin, A.V. Iglovikov. IOP Conference Series: Earth and Environmental Science 19. Ser. Energy Management of Municipal Transportation Facilities and Transport, EMMFT 2017, 012053. (2017)

9. L.I. Inisheva. Agrochemistry, 4, 22-28. (2003)

10. A.V. Petersburg Agrochemistry and physiology of plant nutrition. Moscow: Agricultural production, (1971)

11. V.S. Stankevich Cultural works on the dried lands. Moscow: Rosselkhozizdat, (1977) 